University of Nebraska - Lincoln

DigitalCommons@University of Nebraska - Lincoln

Comparison of dilute acid and ionic liquid pretreatment of switchgrass: Biomass recalcitrance, delignification and enzymatic saccharification

\author{
Chenlin Li \\ Joint BioEnergy Institute \\ Bernhard Knierim \\ Joint BioEnergy Institute \\ Chithra Manisseri \\ Joint BioEnergy Institute \\ Rohit Arora \\ Joint BioEnergy Institute \\ Henrik V. Scheller \\ Joint BioEnergy Institute \\ See next page for additional authors
}

Follow this and additional works at: https://digitalcommons.unl.edu/usdaarsfacpub

Li, Chenlin; Knierim, Bernhard; Manisseri, Chithra; Arora, Rohit; Scheller, Henrik V.; Auer, Manfred; Vogel, Kenneth P.; Simmons, Blake A.; and Singh, Seema, "Comparison of dilute acid and ionic liquid pretreatment of switchgrass: Biomass recalcitrance, delignification and enzymatic saccharification" (2010). Publications from USDA-ARS / UNL Faculty. 1957.

https://digitalcommons.unl.edu/usdaarsfacpub/1957

This Article is brought to you for free and open access by the U.S. Department of Agriculture: Agricultural Research Service, Lincoln, Nebraska at DigitalCommons@University of Nebraska - Lincoln. It has been accepted for inclusion in Publications from USDA-ARS / UNL Faculty by an authorized administrator of DigitalCommons@University of Nebraska - Lincoln. 


\section{Authors}

Chenlin Li, Bernhard Knierim, Chithra Manisseri, Rohit Arora, Henrik V. Scheller, Manfred Auer, Kenneth P. Vogel, Blake A. Simmons, and Seema Singh 


\title{
Comparison of dilute acid and ionic liquid pretreatment of switchgrass: Biomass recalcitrance, delignification and enzymatic saccharification
}

\author{
Chenlin $\mathrm{Li}^{\mathrm{a}}{ }^{\mathrm{b}}$, Bernhard Knierim ${ }^{\mathrm{a}}$, Chithra Manisseri ${ }^{\mathrm{a}}$, Rohit Arora ${ }^{\mathrm{a}}$, Henrik V. Scheller ${ }^{\mathrm{a}}$, \\ Manfred Auer ${ }^{\mathrm{a}}$, Kenneth P. Vogel ${ }^{\mathrm{c}}$, Blake A. Simmons ${ }^{\mathrm{a}, \mathrm{b}}$, Seema Singh ${ }^{\mathrm{a}, \mathrm{b}, *}$ \\ a Joint BioEnergy Institute, Physical Biosciences Division, Lawrence Berkeley National Laboratory, Emeryville, CA, United States \\ ${ }^{\mathrm{b}}$ Sandia National Laboratories, Biomass Science and Conversion Technology Department, Livermore, CA, United States \\ ${ }^{\mathrm{c}}$ United States Department of Agriculture, Grain, Forage and Bioenergy Research Unit, USDA-ARS, University of Nebraska, Lincoln, NE, United States
}

\section{A R T I C L E I N F O}

\section{Article history:}

Received 9 August 2009

Received in revised form 22 October 2009

Accepted 23 October 2009

Available online 30 November 2009

\section{Keywords:}

Pretreatment

Ionic liquid

Dilute acid

Comparison

Enzymatic saccharification

\begin{abstract}
A B S T R A C T
The efficiency of two biomass pretreatment technologies, dilute acid hydrolysis and dissolution in an ionic liquid, are compared in terms of delignification, saccharification efficiency and saccharide yields with switchgrass serving as a model bioenergy crop. When subject to ionic liquid pretreatment (dissolution and precipitation of cellulose by anti-solvent) switchgrass exhibited reduced cellulose crystallinity, increased surface area, and decreased lignin content compared to dilute acid pretreatment. Pretreated material was characterized by powder X-ray diffraction, scanning electron microscopy, Fourier transform infrared spectroscopy, Raman spectroscopy and chemistry methods. Ionic liquid pretreatment enabled a significant enhancement in the rate of enzyme hydrolysis of the cellulose component of switchgrass, with a rate increase of 16.7 -fold, and a glucan yield of $96.0 \%$ obtained in $24 \mathrm{~h}$. These results indicate that ionic liquid pretreatment may offer unique advantages when compared to the dilute acid pretreatment process for switchgrass. However, the cost of the ionic liquid process must also be taken into consideration.
\end{abstract}

Published by Elsevier Ltd.

\section{Introduction}

Lignocellulosic biomass has the potential to serve as a low cost and renewable feedstock for bioconversion into fermentable sugars, which can be further utilized for biofuel production (Gomez et al., 2008; Wyman et al., 2005). It is estimated that there is over one billion tons of biomass available for conversion into biofuels on a renewable basis to displace a substantial portion of the fossil fuels currently consumed within the transportation sector (Simmons et al., 2008). Loss of sugars during pretreatment, and the inability of current pretreatment methods to effectively decrystallize cellulose, result in high costs of sugars derived from biomass. The difficulty in developing effective biomass pretreatment processes is due to the presence of lignin, the crystallinity of the cellulose, and the presence of covalent cross-linkages between lignin and hemicelluloses in the plant cell wall (Blanch and Wilke, 1982). These factors limit the extent to which efficient enzymatic hydrolysis of polysaccharides into sugars can occur. An efficient pretreatment strategy includes: (1) disrupting and removing the cross-linked matrix of lignin and hemicelluloses that embeds the

\footnotetext{
* Corresponding author. Address: Sandia National Laboratories, Biomass Science and Conversion Technology Department, Livermore, CA, United States.

E-mail address: seesing@sandia.gov (S. Singh).
}

cellulose fibers, (2) disrupting hydrogen bonds in crystalline cellulose, and (3) increasing the porosity and surface area of cellulose for subsequent enzymatic hydrolysis.

Several physical and chemical pretreatment methods are currently employed to overcome the recalcitrance of lignocellulose, increase enzyme efficiency and improve the yields of monomeric sugars. These include dilute acid (Grohmann et al., 1985; Lloyd and Wyman, 2005; Schell et al., 2003), ammonia fiber expansion (Dale and Moreira, 1982; Lau et al., 2008), hot water (Bobleter et al., 1976; Liu and Wyman, 2004), lime (Chang et al., 1997; Sierra et al., 2009) and organic solvent (Connors et al., 1980; Zhang et al., 2007) pretreatment technologies. Among these techniques, dilute sulfuric acid pretreatment has been shown as a leading pretreatment process that is currently under commercial development. Sulfuric acid pretreatment solubilizes the hemicelluloses and thereby disrupts the lignocellulosic composite material linked by covalent bonds, hydrogen bonds, and van der Waals forces. However, it can result in the formation of polysaccharide degradation products that are often inhibitory to downstream fermentation organisms and lower the overall sugar yields (Fengel and Wegener, 1984; Ramos, 2003). Furthermore, the condensed lignin remains on the surface of crystalline cellulose following dilute acid pretreatment, which can potentially block enzyme accessibility to the substrate for sugar production (Liu and Wyman, 2004; Zhu et al., 2009). 
Recently, ionic liquids have demonstrated great promise as efficient solvents for biomass dissolution with easy recovery of cellulose upon anti-solvent addition (Dadi et al., 2006; Lee et al., 2009; Li et al., 2009; Liu and Chen, 2006; Singh et al., 2009; Sun et al., 2009; Zhao et al., 2009). Room temperature ionic liquids are organic salts that are in a liquid state at room temperature and are stable up to approximately $300{ }^{\circ} \mathrm{C}$ (Dadi et al., 2006; Lee et al., 2009). We have recently shown that the ionic liquid, 1-ethyl-3-methylimidazolium acetate ([C2mim][OAc]), can effectively solubilize switchgrass, a leading candidate as an energy crop (Sarath et al., 2008), and reject lignin from the recovered polysaccharides (Singh et al., 2009). This process resulted in a product that was efficiently hydrolyzed using a commercial cellulase mixture. Furthermore, several recent reports also studied the complete dissolution and partial delignification of sugarcane, softwood and hardwood in the various ionic liquids (Lee et al., 2009; Sun et al., 2009; Tan et al., 2009).

To investigate the chemical and physical changes features of lignocellulosic biomass as a function of pretreatment, Kumar et al. (2009) have characterized and compared the corn stover and poplar solids resulting from several leading pretreatments including dilute acid, ammonia fiber expansion, ammonia recycled percolation, lime and $\mathrm{SO}_{2}$ technologies. To date, however, no comprehensive comparative analysis has been conducted in order to evaluate any of these leading techniques with the novel ionic liquid biomass pretreatment process. In addition, performances of different pretreatments may vary with feedstock types, the mechanisms of how the leading techniques and ionic liquid act on switchgrass, cause the changes of substrate features, disrupt the lignin-carbohydrate linkages, and impact on subsequent enzymatic hydrolysis have not been researched well. Thus, here we compare the products after ionic liquid and dilute acid pretreatments of switchgrass, and compare their resultant saccharification efficiencies into fermentable sugars. The primary focus of this work is to gain a better understanding of both techniques and judge their feasibility for downstream biofuel production. Characterization of the recovered products was performed to determine glucan, xylan and lignin contents of switchgrass recovered from both pretreatment techniques. Physical characteristics including cellulose crystallinity and plant cell wall morphology were also measured and compared using X-ray diffraction (XRD), scanning electron microscopy (SEM), Fourier transform infrared spectroscopy (FTIR) and Raman spectroscopy.

\section{Methods}

\subsection{Materials and preparation}

Switchgrass (Panicum virgatum L.), supplied by the laboratory of Dr. Ken Vogel at the United States Department of Agriculture, Lincoln, NE, was milled with a Thomas-Wiley Mini Mill fitted with a 40-mesh screen (Model 3383-L10 Arthur H. Thomas Co., Philadelphia, PA, USA). An exhaustive extraction process with water followed by ethanol was performed using the Laboratory Analytical Procedure documented by National Renewable Energy Laboratory (NREL) (Ruiz et al., 2005). Extracted switchgrass was lyophilized at $-50{ }^{\circ} \mathrm{C}$ for at least $24 \mathrm{~h}$ until all the residual solvent evaporated to avoid influence of the moisture content. The samples were stored at $4{ }^{\circ} \mathrm{C}$ in a sealed plastic bag for use in all experimentation.

Cellulase (NS50013) and $\beta$-glucosidase (NS50010) were provided free of charge by Novozymes (Davis, CA). Ionic liquid, 1-ethyl-3-methylimidazolium acetate ([C2mim][OAc]), acetic acid, sodium acetate, sulfuric acid, 3,5-dinitrosalicylic acid (DNS), trifluoroacetic acid (TFA) and sodium hydroxide were purchased from Sigma-Aldrich (St. Louis, MO).

\subsection{Switchgrass pretreatments and regeneration}

\subsubsection{Ionic liquid pretreatment}

A $3 \%(w / w)$ switchgrass solution was prepared by combining $300 \mathrm{mg}$ of switchgrass with $9.7 \mathrm{~g}$ [C2mim] [OAc] in a $50 \mathrm{~mL}$ autoclave vial. The vials and the contents were heated and stirred in an oil bath at $160{ }^{\circ} \mathrm{C}$ for $3 \mathrm{~h}$. All experiments were conducted in triplicates. After $3 \mathrm{~h}$ incubation, $30 \mathrm{~mL}$ of deionized water was slowly added into the stirred biomass/[C2mim][OAc] slurry for regeneration of the dissolved cellulose from switchgrass. A precipitate immediately formed, and the sample was centrifuged at $10,000 \mathrm{~g}$ for $10 \mathrm{~min}$. The supernatant containing ionic liquid was removed, and the precipitate was washed four times with additions of water in order to ensure that excess ionic liquid had been removed. Presence of ionic liquid was verified by measuring the absorbance (Shimadzu UV-2401) of the recovered liquid.

To understand the impact of ionic liquid pretreatment and dissolution of hemicelluloses, a TFA hydrolysis was performed. All of the supernatants from the five wash steps were collected and concentrated, and then $300 \mu \mathrm{L}$ of solution was treated with $150 \mu \mathrm{L}$ of TFA at $120^{\circ} \mathrm{C}$ for $1 \mathrm{~h}$. The hydrolyzed solution was centrifuged at $10,000 \mathrm{~g}$ for $10 \mathrm{~min}$, and the supernatant was analyzed using highpressure anion exchange chromatography (HPAEC) for the monosaccharide analysis after evaporation of the TFA residues in a CentriVap Vacuum Concentrator (Labconco Corp, MO) at $30^{\circ} \mathrm{C}$ overnight.

\subsubsection{Dilute acid pretreatment}

The switchgrass samples were presoaked in pressurized glass tubes at room temperature in $1.2 \%(\mathrm{w} / \mathrm{w})$ sulfuric acid at $3 \%(\mathrm{w} /$ w) total solid loading for at least $4 \mathrm{~h}$. The glass tubes were then heated in an oil bath at $160{ }^{\circ} \mathrm{C}$ for $20 \mathrm{~min}$ with three replicates. The acidic slurry was filtered through Whatman filter paper with a Buchner funnel. The filtrates were stored at $4{ }^{\circ} \mathrm{C}$ prior to sugar analysis by HPAEC. The recovered solids were washed with deionized water until the $\mathrm{pH}$ of the washed water reached 6.0 (Lloyd and Wyman, 2005). The buffer solution used in the enzymatic saccharification (see below) was used for the final washes.

For both pretreatment processes, the recovered product was lyophilized at $-50{ }^{\circ} \mathrm{C}$ for $48 \mathrm{~h}$ before compositional analysis.

\subsection{Enzymatic saccharification}

Batch enzymatic saccharification of pretreated and untreated switchgrass samples were carried out at $50^{\circ} \mathrm{C}$ and $150 \mathrm{rpm}$ in a reciprocating shaker. All samples were diluted to 5 g glucan per liter in a $50 \mathrm{mM}$ sodium acetate buffer with a $\mathrm{pH}$ of 4.8 supplemented with $0.08 \mathrm{~g} / \mathrm{L}$ Tetracycline solution for enzymatic hydrolysis. The total batch volume was $5 \mathrm{~mL}$ with cellulase (NS50013) concentration of $50 \mathrm{mg}$ protein/g glucan and $\beta$-glucosidase (NS50010) concentration of $5 \mathrm{mg}$ protein/g glucan. The reaction was monitored by taking $50 \mu \mathrm{L}$ supernatant at specific time intervals, followed by centrifugation at $10,000 \mathrm{~g}$ for $5 \mathrm{~min}$, and measuring the release of reducing sugars by DNS assay that uses D-glucose as a standard (Miller, 1959). The untreated switchgrass controls were run concurrently with all recovered samples to eliminate potential differences in temperature history or enzyme loading (Dadi et al., 2006). The initial rates of total soluble reducing sugar formation are calculated based on the sugar released in the first 30 min of hydrolysis (Dadi et al., 2006). All assays are performed in triplicate. Error bars show the standard deviation of triplicate measurements.

\subsection{Chemical characterization of switchgrass}

The compositional analysis of switchgrass before and after pretreatment was performed using the NREL procedures LAP-002 and 005 (Sluiter et al., 2004a, b). Absorbance reading of acid soluble 
lignin was taken at $205 \mathrm{~nm}$ using a UV-Vis spectrophotometer (Shimadzu UV-2401) with high purity quartz cuvettes with a $1 \mathrm{~cm}$ pathlength. The extinction coefficient of $110 \mathrm{~L} / \mathrm{g} \mathrm{cm}$ was used for the calculation of acid soluble lignin for switchgrass (Suryawati et al., 2009). The monosaccharides produced in the solutions from both ionic liquid (after TFA hydrolysis) and dilute acid pretreatment were analyzed by HPAEC on an ICS-3000 system equipped with an electrochemical detector and a $4 \times 250 \mathrm{~mm}$ CarboPac PA20 analytical column (Dionex), essentially according to (Obro et al., 2004). Elution was initiated with $97.2 \%(\mathrm{v} / \mathrm{v})$ water and $2.8 \%(\mathrm{v} / \mathrm{v}) 1 \mathrm{M} \mathrm{NaOH}$ for first $15 \mathrm{~min}$, with $20 \mu \mathrm{L}$ injection volume. Elute concentration was then switched to $55.0 \%(\mathrm{v} / \mathrm{v})$ water and 45.0\% (v/v) $1 \mathrm{M} \mathrm{NaOH}$ for next $20 \mathrm{~min}$ and returned to $97.2 \%(\mathrm{v} /$ v) water and $2.8 \%(\mathrm{v} / \mathrm{v}) 1 \mathrm{M} \mathrm{NaOH}$ for the last $10 \mathrm{~min}$ to equilibrate the column. The flow rate was $0.5 \mathrm{~mL} / \mathrm{min}$.

\subsection{Crystallinity measurement}

X-ray powder diffraction patterns of both untreated and pretreated SG were obtained using a Scintag diffractometer. SG samples were casted with double sided tape on microscope slides. Scans were collected at $45 \mathrm{kV}$ and $40 \mathrm{~mA}$ with a step size of $0.02^{\circ}$ and step of $0.5 \mathrm{~s}$. Switchgrass crystallinity, as expressed by crystallinity index (CrI), was determined from XRD data and calculated using the formula (Segal et al., 1959):

$\mathrm{CrI}=\frac{I_{002}-I_{a m}}{I_{002}} \times 100$

In which, $I_{002}$ is the intensity for the crystalline portion of biomass (cellulose) at about $2 \theta=22.5$, and $I_{a m}$ is the peak for the amorphous portion (i.e., cellulose, hemicelluloses and lignin) at about $2 \theta=16.6$. In this study, the second highest peak after $2 \theta=22.5$ was at $2 \theta=16.6$, and was assumed to correspond to the amorphous region (Kumar et al., 2009).

\subsection{Scanning electron microscopy (SEM)}

SEM images were taken for both untreated and pretreated switchgrass solids (dried powder of particle size $<400 \mu \mathrm{m}$ ) using a Hitachi S-5000 microscope. Prior to acquiring images, the samples were mounted with double sided carbon tape on precut brass sample stubs and sputter coated with approximately 30 Angstrom of $\mathrm{Au} / \mathrm{Pd}$. The representative images of dilute acid and ionic liquidpretreated switchgrass reported here were acquired with a $10 \mathrm{kV}$ accelerating voltage.

\subsection{ATR-FTIR spectroscopy}

Attenuated total reflection-Fourier transform infrared spectroscopy (ATR-FTIR) was conducted using a Bruker Optics Vertex system with built-in diamond-germanium ATR single reflection crystal. Untreated and pretreated SG samples were pressed uniformly against the diamond surface using a spring-loaded anvil. Sample spectra were obtained in triplicates using an average of 128 scans over the range between $850 \mathrm{~cm}^{-1}$ and $2000 \mathrm{~cm}^{-1}$ with a spectral resolution of $2 \mathrm{~cm}^{-1}$. Air, water and ionic liquid solution were used as background for untreated and pretreated switchgrass samples, respectively. Baseline correction was conducted using the rubberband correction method following the spectrum minima (Singh et al., 2009).

\subsection{Raman spectroscopy}

Raman spectra were measured using a LabRam HR 800 (Horiba Jobin Yvon, Edison, NJ). The spectrometer is equipped with a confocal microscope and a CCD detector. The samples were excited with a $785 \mathrm{~nm}$ diode laser. The confocal pinhole diameter of $200 \mu \mathrm{m}$ and exposure time of $60 \mathrm{~s}$ is used for all experiments. All samples were scanned in triplicates. LabSpec software was used to obtain Raman spectra in specific spectral ranges between $1500 \mathrm{~cm}^{-1}$ and $1700 \mathrm{~cm}^{-1}$. Area intensities of the bands at 1600 and $1629 \mathrm{~cm}^{-1}$ were calculated after baseline correction and with rubberband correction method and curve fitting using LevenbergMarquardt Algorithm (Bruker Opus software).

\section{Results and discussion}

\subsection{Compositional analysis}

For ionic liquid pretreatment, previous studies have found that (1) [C2mim] $[\mathrm{OAc}]$ is an effective solvent to solubilize the plant cell wall at mild temperature (Singh et al., 2009), (2) subsequent cellulose precipitation and regeneration via addition of water as antisolvent could reject lignin in the solution significantly based on the imaging techniques (Singh et al., 2009), (3) the optimal reaction temperature and time for switchgrass are $160^{\circ} \mathrm{C}$ and $3 \mathrm{~h}$. Although the acid pretreatment conditions used in this study are known to produce enzymatically digestible biomass (Lloyd and Wyman, 2005), they have not been specifically optimized for switchgrass.

Table 1 summarizes the various pretreatment conditions and the amounts of each major cell wall component in switchgrass before and after pretreatment. Results show that when compared with the untreated materials, both dilute acid and ionic liquid pretreatment remove lignin and hemicellulose and produce higher glucan content, ranging from $50.4 \%$ to $67.7 \%$. Ionic liquid pretreatment removes more lignin and less hemicellulose than dilute acid pretreatment, producing recovered material with lower levels of residual lignin (13.6\% vs. $28.5 \%$, respectively) and higher levels of residual xylan (7.6\% vs. $4.4 \%$, respectively).

The recovered switchgrass samples have significantly reduced lignin content compared to the untreated switchgrass. During dilute acid pretreatment, total lignin was decreased by $22.4 \%$, with $13.7 \%$ of acid soluble lignin and $8.7 \%$ of Klason lignin. In comparison, ionic liquid pretreatment removed $69.2 \%$ of total lignin with $12.0 \%$ of acid soluble lignin and $57.2 \%$ of Klason lignin. These results show that ionic liquid pretreatment results in significant level of delignification. A recent study has investigated the [C2mi$\mathrm{m}][\mathrm{OAc}]$ dissolution of pine and oak wood materials at $110^{\circ} \mathrm{C}$ for $16 \mathrm{~h}$, and achieved lignin reduction of $26.1 \%$ for pine and $34.9 \%$ for oak (Sun et al., 2009), which were lower than the delignification efficiency of $69.2 \%$ for switchgrass at $160{ }^{\circ} \mathrm{C}$ for $3 \mathrm{~h}$ in this study. Similarly, Lee et al. (2009) used [C2mim][OAc] as a solvent to extract the lignin from maple wood flour, and were able to extract $85 \%$ of lignin after $70 \mathrm{~h}$ pretreatment at $90{ }^{\circ} \mathrm{C}$. In addition, another paper reported 93\% lignin extraction efficiency from sugarcane plant waste using 1-ethyl-3-methylimidazolium alkylbenzenesulfonate at $190^{\circ} \mathrm{C}$ for $2 \mathrm{~h}$ (Tan et al., 2009). We hypothesize that the differences in the reported delignification efficiency are likely due to the following reasons: (1) the more effective pretreatments are generally those that employ higher temperatures and incubation times, indicating that there may be en effective lignin glass transition temperature that must be exceeded to efficiently solubilize lignin, (2) specific ionic liquids have specific interactions with biomass, and that those interactions are dependent on the cation, anion, temperature, and time used in the pretreatment process, and (3) the extent and degree of biomass recalcitrance varies as a function of the biomass itself (i.e., grass, softwood, and hardwood), and is influenced by inherent variations in terms of age, harvest method, extent of drying, and storage conditions.

Fig. 1 presents sugar yields and monosaccharide composition of dissolved material after dilute acid and ionic liquid pretreatment. 
Table 1

Compositional analysis of untreated and pretreated (dilute acid and ionic liquid) switchgrass ${ }^{\mathrm{a}, \mathrm{b}}$.

\begin{tabular}{|c|c|c|c|c|c|c|c|c|c|}
\hline Method & $\begin{array}{l}\text { Recovered } \\
\text { switchgrass (\%) }\end{array}$ & $\begin{array}{l}\text { Glucan } \\
(\%)\end{array}$ & $\begin{array}{l}\text { Xylan } \\
(\%)\end{array}$ & $\begin{array}{l}\text { Arabinan } \\
(\%)\end{array}$ & $\begin{array}{l}\text { Galactan } \\
(\%)\end{array}$ & $\begin{array}{l}\text { Total } \\
\text { lignin (\%) }\end{array}$ & $\begin{array}{l}\text { Acid-soluble } \\
\text { lignin (\%) }\end{array}$ & $\begin{array}{l}\text { Klason } \\
\text { lignin (\%) }\end{array}$ & $\begin{array}{l}\text { Ashes } \\
(\%)\end{array}$ \\
\hline Untreated & $\begin{array}{l}100 \pm 0.0 \\
(300 \mathrm{mg})\end{array}$ & $\begin{array}{l}39.5 \pm 1.8 \\
(118.5 \mathrm{mg})\end{array}$ & $\begin{array}{c}20.3 \pm 1.4 \\
(60.9 \mathrm{mg})\end{array}$ & $\begin{array}{l}2.1 \pm 0.0 \\
(6.3 \mathrm{mg})\end{array}$ & $\begin{array}{l}2.6 \pm 0.0 \\
(7.8 \mathrm{mg})\end{array}$ & $\begin{array}{l}21.8 \pm 0.2 \\
(65.4)\end{array}$ & $\begin{array}{l}4.0 \pm 0.1 \\
(12.0 \mathrm{mg})\end{array}$ & $\begin{array}{l}17.8 \pm 0.1 \\
(53.4 \mathrm{mg})\end{array}$ & $\begin{array}{l}4.1 \pm 0.1 \\
(12.3 \mathrm{mg})\end{array}$ \\
\hline Dilute acid & $\begin{array}{r}59.3 \pm 1.8 \\
(178 \mathrm{mg})\end{array}$ & $\begin{array}{l}50.4 \pm 1.6 \\
(89.7 \mathrm{mg})\end{array}$ & $\begin{array}{l}4.4 \pm 1.9 \\
(7.9 \mathrm{mg})\end{array}$ & $\begin{array}{l}1.1 \pm 0.0 \\
(1.8 \mathrm{mg})\end{array}$ & $\begin{array}{c}2.4 \pm 0.1 \\
(4.2 \mathrm{mg})\end{array}$ & $\begin{array}{l}28.5 \pm 0.7 \\
(50.8)\end{array}$ & $\begin{array}{l}1.7 \pm 0.5 \\
(3.1 \mathrm{mg})\end{array}$ & $\begin{array}{c}26.8 \pm 0.2 \\
(47.7 \mathrm{mg})\end{array}$ & $\begin{array}{c}2.7 \pm 0.1 \\
(4.9 \mathrm{mg})\end{array}$ \\
\hline Ionic liquid & $\begin{array}{r}49.3 \pm 1.7 \\
(148 \mathrm{mg})\end{array}$ & $\begin{array}{l}67.7 \pm 0.4 \\
(98.7 \mathrm{mg})\end{array}$ & $\begin{array}{l}7.6 \pm 0.3 \\
(11.3 \mathrm{mg})\end{array}$ & $\begin{array}{l}2.1 \pm 0.0 \\
(3.1 \mathrm{mg})\end{array}$ & $\begin{array}{c}2.1 \pm 0.1 \\
(3.1 \mathrm{mg})\end{array}$ & $\begin{array}{c}13.6 \pm 0.9 \\
(20.1 \mathrm{mg})\end{array}$ & $\begin{array}{c}2.8 \pm 0.2 \\
(4.1 \mathrm{mg})\end{array}$ & $\begin{array}{c}10.8 \pm 0.7 \\
(16.0 \mathrm{mg})\end{array}$ & $\begin{array}{l}3.6 \pm 0.1 \\
(5.3 \mathrm{mg})\end{array}$ \\
\hline
\end{tabular}

a The inability to close the initial mass balance is likely due to the protein and other sugars present in the biomass.

b Values in parentheses represent the amount of each component recovered from $300 \mathrm{mg}$ total switchgrass.

The results confirm that the dilute acid process removes the majority of hemicellulose present and small amounts of amorphous cellulose. Our data show the presence of oligosaccharides and only trace levels of monosaccharides present in the ionic liquid washes based on the HPAEC analysis. Upon TFA hydrolysis, HPAEC data confirmed that the oligo- and polysaccharides in the washes are composed mainly of glucose and xylose with small amounts of arabinose and galactose. The hemicellulose removed by ionic liquid is comparable to that observed in the dilute acid pretreatment process.

\subsection{Biomass crystallinity}

Crystallinity is believed to be an important feature affecting enzymatic saccharification of cellulose (Dadi et al., 2007, 2006; Kumar et al., 2009; Zhang and Lynd, 2004). Various pretreatments can change cellulose crystal structures by disrupting inter- and intrachain hydrogen bonding of cellulose fibrils (Mosier et al., 2005). The features of recovered switchgrass after dilute acid and ionic liquid pretreatment were examined using powder X-ray diffraction and also compared to the corresponding untreated samples. Results show that both untreated and dilute acid pretreated switchgrass samples display little or no change in cellulose crystallinity, but the sample obtained after ionic liquid pretreatment is altered significantly and has a broad diffraction peak (Supporting information Fig. S1). The crystallinity index (CrI) for all samples is calculated from the XRD data and the results are summarized in Table 2. As shown, the untreated switchgrass is highly crystalline (26.2 $\mathrm{CrI})$, and after dilute acid pretreatment there is an observed increase in the CrI (39.1 CrI). This increase in CrI after dilute acid prertreatment is consistent with the results reported by Kumar et al. (2009), suggesting that the amorphous cellulose breaks down

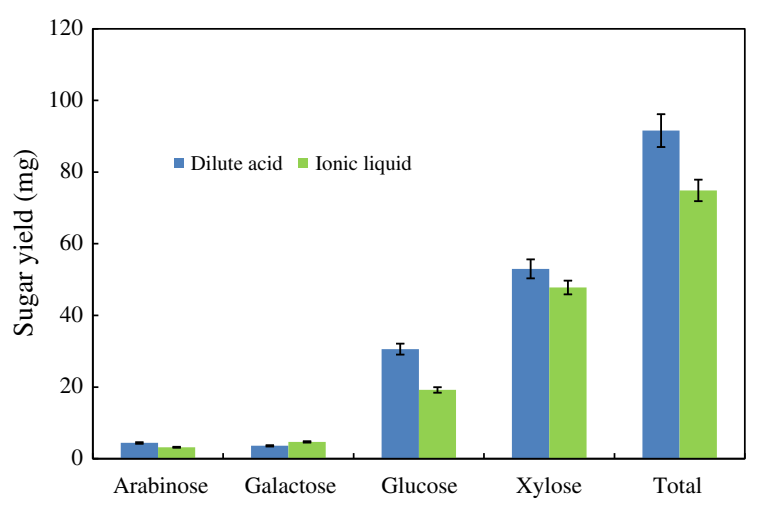

Fig. 1. Yield and monosaccharide composition of dissolved material produced under dilute acid and ionic liquid pretreatment conditions. more under acidic condition but that this pretreatment process is unable to break apart the inter- and intra- chain hydrogen bondings in cellulose fibrils. In the case of IL pretreatment, the peak at $22.5^{\circ}$ (due to the 002 crystalline plane) present in the untreated switchgrass diffraction pattern are significantly weakened and shifted to $20.1^{\circ}$, indicating that there is minimal structural order in the cellulose after ionic liquid pretreatment (Kuo and Lee, 2009; Lee et al., 2009), and is likely due to the transformation from cellulose I to cellulose II (Sun et al., 2009). The CrI calculated from the ionic liquid pretreatment sample is significantly lower (2.6 CrI) than either the untreated or dilute acid pretreated samples. This decrease in cellulose crystallinity indicates that the recovered product is highly amorphous and therefore has an increase in cellulose surface accessibility and would theoretically enable more efficient cellulase hydrolysis.

\subsection{ATR-FTIR and Raman analysis}

Chemical fingerprinting of dilute acid and ionic liquid-pretreated switchgrass and untreated switchgrass were characterized by ATR-FTIR and Raman spectroscopy (Supporting information Fig. S2). For ATR-FTIR data, seven bands are used to monitor the chemical changes of lignin and carbohydrates. When compared to the untreated switchgrass spectrum, the bands at $1510 \mathrm{~cm}^{-1}$ (aromatic skeletal from lignin) and $1329 \mathrm{~cm}^{-1}$ (syringyl and guaiacyl condensed lignin) decrease significantly for ionic liquid-pretreated switchgrass, whereas the acid pretreated biomass still shows significant presence of lignin. In addition to that, the peaks at $1098 \mathrm{~cm}^{-1}$ (referring to the removal of crystalline cellulose) are missing, whereas the peaks at $900 \mathrm{~cm}^{-1}$ (referring to the removal of amorphous cellulose) are increasing for ionic liquid-pretreated switchgrass, which is consistent with the XRD pattern, indicating the decrease of cellulose crystallinity. The spectra obtained after dilute acid pretreatment shows an increase of the crystalline cellulose band at $1098 \mathrm{~cm}^{-1}$ and a reduction of the amorphous band at $900 \mathrm{~cm}^{-1}$, confirming the increase of crystallinity when compared with both untreated and ionic liquid-pretreated switchgrass samples (Kumar et al., 2009; Liu and Chen, 2006). Furthermore, significant decrease of bands intensity are observed at $1056 \mathrm{~cm}^{-1}$ (C-O stretch in cellulose and hemicellulose), $1235 \mathrm{~cm}^{-1}$ (C-O stretching in lignin and hemicellulose) and 1375 (C-H deformation in cellulose and hemicellulose) for the spectra obtained after dilute acid pretreatment, which are likely due to the removal of major hemicelluloses. In comparison, the corresponding bands intensity increase were observed in the spectra of ionic liquid pretreated samples, which could be attributed to the increase of cellulose content as a result of both lignin and hemicelluloses removal. The ratio of the peak areas at two band positions, $1510 / 900 \mathrm{~cm}^{-1}$, was used to estimate the lignin/cellulose ratio and was compared with the results obtained by compositional analysis in Table 3 (Pandey and Pitman, 2004). The compositional results show that when 
Table 2

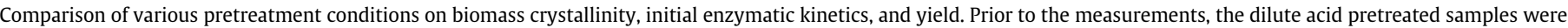
recovered by filtration and the ionic liquid pretreated samples were recovered after precipitation with water.

\begin{tabular}{|c|c|c|c|c|c|}
\hline \multirow[t]{2}{*}{ Pretreatment method } & \multirow[t]{2}{*}{ Crystallinity index } & \multirow[t]{2}{*}{ Initial enzymatic rate $(\mathrm{mg} / \mathrm{L} / \mathrm{min})$} & \multirow[t]{2}{*}{ Rate enhancement } & \multicolumn{2}{|l|}{ Enzymatic hydrolysis } \\
\hline & & & & Reducing sugar (mg) & Digestibility (\%) \\
\hline Untreated & 26.2 & $0.3 \pm 0.03$ & - & $0.8 \pm 0.1$ & 2.7 \\
\hline Dilute acid & 39.1 & $1.1 \pm 0.1$ & 3.3 & $13.2 \pm 1.1$ & 47.6 \\
\hline Ionic liquid & 2.6 & $18.5 \pm 1.6$ & 54.4 & $24.0 \pm 2.1$ & 96.0 \\
\hline
\end{tabular}

a Calculated on the basis of glucan content during the first $24 \mathrm{~h}$.

Table 3

Comparison of Lignin/cellulose ratio using FTIR and analytical chemistry characterization methods. Prior to the measurements, the dilute acid pretreated samples were recovered by filtration and the ionic liquid pretreated samples were recovered after precipitation with water.

\begin{tabular}{llll}
\hline Analytical methods & \multicolumn{2}{l}{ Pretreatment } & \\
\cline { 2 - 4 } & Untreated & Dilute acid & Ionic liquid \\
\hline FTIR $^{\mathrm{a}}$ & $0.49 \pm 0.07$ & $0.68 \pm 0.05$ & $0.13 \pm 0.01$ \\
Wet chemistry & $0.55 \pm 0.05$ & $0.57 \pm 0.04$ & $0.20 \pm 0.01$ \\
\hline
\end{tabular}

a The ratio of area at band positions of $1510 / 900 \mathrm{~cm}^{-1}$.

compared to the untreated sample, ionic liquid pretreatment decreases the lignin/cellulose ratio from 0.55 to 0.20 , whereas dilute acid pretreatment increases the ratio to 0.57 . FTIR analysis further confirms delignification with the ratio decreasing from 0.49 (untreated switchgrass) to 0.13 (ionic liquid pretreatment), but are observed to increase to 0.68 for dilute acid pretreatment. Previous in situ imaging observations have also shown the disruption of covalent linkages between lignin and cellulose (Singh et al., 2009).

Raman spectra of untreated and pretreated switchgrass samples provide molecular level understanding of delignification during pretreatment (Supporting information Fig. S1B). Two main lignin features are monitored that correspond to lignin aromatic ring stretch mode $\left(1600 \mathrm{~cm}^{-1}\right)$ and ring-conjugated $\mathrm{C}=\mathrm{C}$ bond in coniferaldehyde $\left(1620 \mathrm{~cm}^{-1}\right)$, respectively (Adapa et al., 2009). Ionic liquid regenerated switchgrass clearly shows diminished $\mathrm{C}=\mathrm{C}$ bond in coniferaldehyde, as indicated by the missing band at $1620 \mathrm{~cm}^{-1}$, and also significant breakage/modification of the aromatic ring. However, for dilute acid pretreatment, only a slight decrease of these two lignin bands are observed when compared with untreated and ionic liquid-pretreated switchgrass. Table 4 shows the various lignin removals as calculated by the area intensity of the two lignin peaks. Dilute acid pretreatment results in reduction of lignin aromatic ring by $1.4 \%\left(1600 \mathrm{~cm}^{-1}\right)$ and coniferaldehyde by $48.8 \%\left(1620 \mathrm{~cm}^{-1}\right)$, respectively. In comparison, ionic liquid pretreatment achieved $77.0 \%$ of lignin aromatic ring removal and higher than $90 \%$ of coniferaldehyde removal. These findings are in agreement with the lignin removal efficiency by analytical chemistry and absorbance methods.

These results clearly demonstrate that the ionic liquid pretreatment effectively weakens the van der Waals interaction between cell wall polymers. Arabinoxylan, the most abundant hemicellulose in grasses, forms covalent linkages with lignin through ferulate ester side groups and it is possible that these linkages are disrupted during ionic liquid pretreatment and generate the low lignin product recovered (Porchia et al., 2002). However, other interactions between matrix polysaccharides, cellulose and lignin may also be affected.

\subsection{Scanning electron microscopy}

SEM images of untreated, ionic liquid and dilute acid pretreated switchgrass were taken at $5000 \times$ magnification (Supporting information Fig. S3). The results show that the untreated ground switchgrass has a highly fibrillar and intact morphology. However, cell wall structure is not disrupted by dilute acid pretreatment. The major microfibrous cellulose structures are preserved, and some lignin or lignin carbohydrate complexes may be condensed on the surface of cellulose fibers (Zhu et al., 2009). In contrast, ionic liquid pretreatment significantly alters the fibrillar structure. The ionic liquid pretreated sample shows no fibrous structure and there are pores observed over several length scales. These results are consistent with the observations that faster hydrolysis rates and higher glucan yields are obtained for ionic liquid pretreated biomass than for dilute acid pretreated biomass, which will be discussed as follows.

\subsection{Comparison of the enzymatic saccharification process by two different pretreatments}

Enzymatic hydrolysis of both acid and ionic liquid-pretreated switchgrass to reducing sugar was carried out to compare their initial kinetics and cellulose digestibility. Fig. 2 shows total reducing sugar production and cellulose digestibility profiles for untreated and pretreated switchgrass from ionic liquid and dilute acid at the same enzyme loading. Taking into account the hydrolysis reaction stoichiometry, $1 \mathrm{~g}$ of cellulose upon complete hydrolysis produces $1.11 \mathrm{~g}$ of glucose (Dadi et al., 2006). Ionic liquid-pretreated switchgrass exhibited significantly higher saccharification kinetics, with cellulose digestibility reaching $96.0 \%$ within $24 \mathrm{~h}$, whereas digestibility of dilute acid pretreated switchgrass only reached $47.6 \%$ over the same time interval. The initial rates of hydrolysis to soluble reducing sugar are shown in Table 2. Initial rates of ionic liquid were 16.7 times greater than dilute acid pretreatment and up to 54.4 times greater than untreated switchgrass.

The loss of intra- and inter-molecular hydrogen bonding resulting in amorphous cellulose provides an enhanced surface area leading to better enzyme accessibility and increased binding sites in recovered cellulose fibers. The difference in the hydrolysis rates and amounts of total reducing sugars released from two different pretreatments can be attributed to the differences in the ensuing

Table 4

Raman intensity data indicating lignin removal.

\begin{tabular}{|c|c|c|c|c|}
\hline Samples & Area intensity at $1600 \mathrm{~cm}^{-1}$ & Relative change at $1600 \mathrm{~cm}^{-1}(\%)$ & Area intensity at $1620 \mathrm{~cm}^{-1}$ & Relative change at $1620 \mathrm{~cm}^{-1}(\%)$ \\
\hline Untreated & $244,799 \pm 43,242$ & - & $85,498 \pm 15,111$ & - \\
\hline Dilute acid & $241,382 \pm 38,272$ & 1.4 & $43,768 \pm 6939$ & 48.8 \\
\hline Ionic liquid & $56,311 \pm 13,282$ & 77.0 & Undetectable & $>90 \%$ \\
\hline
\end{tabular}




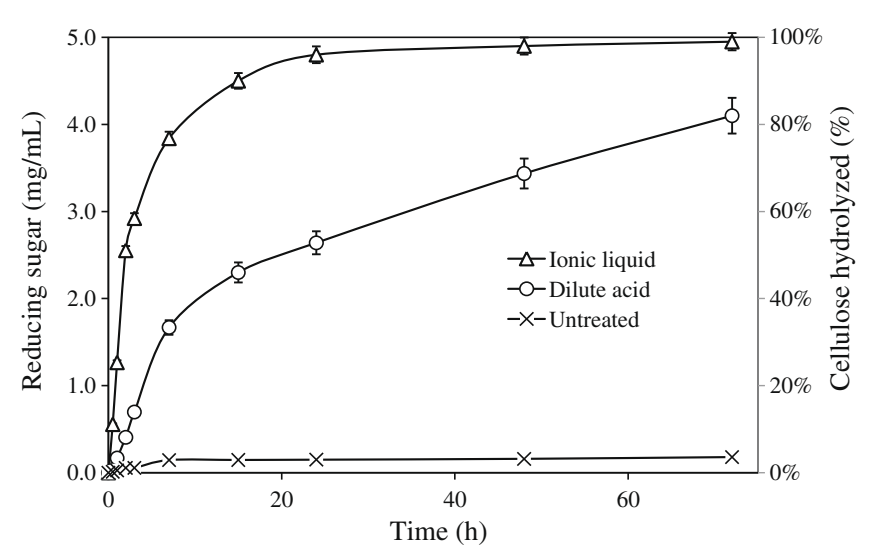

Fig. 2. Comparison of enzymatic saccharification by various pretreatments.

Table 5

Total processing time (pre-treatment + enzymatic hydrolysis) to recover $85 \%$ of the glucan from cellulose using various pretreatment methods.

\begin{tabular}{llll}
\hline $\begin{array}{l}\text { Pretreatment } \\
\text { method }\end{array}$ & $\begin{array}{l}\text { Pretreatment } \\
\text { time }(\mathrm{h})\end{array}$ & $\begin{array}{l}\text { Saccharification } \\
\text { time }(\mathrm{h})\end{array}$ & $\begin{array}{l}\text { Total process } \\
\text { time }(\mathrm{h})\end{array}$ \\
\hline $\begin{array}{l}\text { Untreated } \\
\text { Dilute acid }\end{array}$ & - & - & - \\
Ionic liquid & 0.33 & $>72$ & $>72$ \\
\hline
\end{tabular}

cellulose structures of amorphous cellulose from ionic liquid pretreatment and largely crystalline cellulose from dilute acid pretreated biomass (Li et al., 2009; Liu and Chen, 2006; Zhao et al., 2009). Table 2 further shows that increase or decrease of enzymatic hydrolysis rate and glucan digestibility leads to a corresponding decrease or increase of CrI obtained from XRD measurement. Furthermore, lignin could also act as a major obstacle to enzyme attack on cellulose and can irreversibly adsorb cellulase (Lee et al., 2009). In this study, our results suggest a strong correlation between the hydrolysis kinetics and delignification efficiency, which is consistent with the observations of Lee et al. (2009).

Hydrolysis results clearly showed that soluble sugars were released faster and to a greater extent in the ionic liquid-pretreated switchgrass than in the dilute acid pretreated switchgrass studied here. Additional reductions in enzyme loading, low cost ionic liquids, and recovery of the ionic liquid are essential to promote the economy of biorefineries and develop the optimal ionic liquid pretreatment. Table 5 shows the total processing time to achieve an $85 \%$ glucose recovery from the cellulose under various pretreatments. Although effective dilute acid pretreatment occurred in $20 \mathrm{~min}$, the total processing time to reach $85 \%$ glucose yield went up to over $72 \mathrm{~h}$. In contrast, for ionic liquid pretreatment, the total processing time amounts to only $15 \mathrm{~h}$. The application of this novel pretreatment for biofuel production therefore appears to offer several advantages when compared to dilute acid: it is more convenient and environmentally friendly, requires less processing time, lowers energy consumption and leads to a higher yield of sugar production. These advantages need to be counterbalanced by the higher cost associated with the ionic liquid, but offer further motivation to explore and develop this pretreatment technology. Furthermore, the significant delignification efficiency demonstrated by ionic liquid pretreatment likely suggests a promising aspect for recovering and converting lignin as a valuable commercial co-product.

\section{Conclusion}

Pretreatment of biomass is an extremely important step in a commercial biorefinery, and for massive realization of lignocellu- losic biomass as alternative fuel source to occur, fundamental understanding and comparison of various pretreatment processes is essential. A side-by-side comparison of ionic liquid and acid pretreatments of switchgrass indicates that the ionic liquid pretreatment is a promising alternative to the dilute acid pretreatment process in terms of total process time to produce high yields of sugar from the recovered product. In contrast to dilute acid pretreatment, the recovered biomass from ionic liquid pretreatment of switchgrass was significantly disrupted, has a high surface area, is essentially amorphous in terms of cellulose crystallinity, resulted in three times more delignification, and produced significant enhancement of enzyme hydrolysis kinetics by a factor of 16.7. Ionic liquid pretreatment is a relatively new technique, and there is much to be discovered before a commercially viable process is realized. However, it is apparent that besides being environmentally benign, ionic liquid pretreatment may offer several advantages over acid pretreatment in terms of total processing time and the prospect of realizing a consolidated process with less degradation of monosaccharides, and consequently minimum inhibitory product formation for the downstream saccharification step.

\section{Acknowledgements}

The authors thank Novozymes for the gift of the cellulase cocktails used in this work. The authors thank Dr. Shunlin Wang from Bruker Optics, Drs. Andreia M Smith and Lan Sun from the Joint BioEnergy Institute for the suggestions and discussion on FTIR and Raman analysis. This work was part of the DOE Joint BioEnergy Institute (http://www.jbei.org) supported by the US Department of Energy, Office of Science, Office of Biological and Environmental Research, through Contract DE-AC02-05CH11231 between Lawrence Berkeley National Laboratory and the US Department of Energy.

\section{Appendix A. Supplementary material}

Supplementary data associated with this article can be found, in the online version, at doi:10.1016/j.biortech.2009.10.066.

\section{References}

Adapa, P.K., Karunakaran, C., Tabil, L.G., Schoenau, G.J., 2009. Potential Applications of Infrared and Raman Spectromicroscopy for Agricultural Biomass. Agricultural Engineering International: the CIGR Ejournal Manuscript 1081, Vol. XI (February), pp. 1-25.

Blanch, H.W., Wilke, C.R., 1982. Sugars and chemicals from cellulose. Reviews in Chemical Engineering, 71-119.

Bobleter, O., Niesner, R., Rohr, M., 1976. Hydrothermal degradation of cellulosic matter to sugars and their fermentative conversion to protein. Journal of Applied Polymer Science 20, 2083-2093.

Chang, V.S., Burr, B., Holtzapple, M.T., 1997. Lime pretreatment of switchgrass. Applied Biochemistry and Biotechnology 63-65, 3-19.

Connors, W.J., Johanson, L.N., Sarkanen, K.V., Winslow, P., 1980. Thermaldegradation of Kraft Lignin in tetralin. Holzforschung 34, 29-37.

Dadi, A.P., Schall, C.A., Varanasi, S., 2007. Mitigation of cellulose recalcitrance to enzymatic hydrolysis by ionic liquid pretreatment. Applied Biochemistry and Biotechnology 137, 407-421.

Dadi, A.P., Varanasi, S., Schall, C.A., 2006. Enhancement of cellulose saccharification kinetics using an ionic liquid pretreatment step. Biotechnology and Bioengineering 95, 904-910.

Dale, B.E., Moreira, M.J., 1982. A freeze-explosion technique for increasing cellulose hydrolysis. Biotechnology and Bioengineering Symposium 31, 43.

Fengel, D., Wegener, G., 1984. Wood: Chemistry Ultrastructure, Reactions. W. de Gruyter, Berlin, New York.

Gomez, L.D., Steele-King, C.G., McQueen-Mason, S.J., 2008. Sustainable liquid biofuels from biomass: the writing's on the walls. New Phytologist 178, 473-485.

Grohmann, K., Torget, R., Himmel, M., 1985. Dilute acid pretreatment of biomass at high solids concentrations. Biotechnology and Bioengineering Symposium 59, 80.

Kumar, R., Mago, G., Balan, V., Wyman, C.E., 2009. Physical and chemical characterizations of corn stover and poplar solids resulting from leading pretreatment technologies. Bioresource Technology 100, 3948-3962.

Kuo, C.H., Lee, C.K., 2009. Enhancement of enzymatic saccharification of cellulose by cellulose dissolution pretreatments. Carbohydrate Polymers 77, 41-46. 
Lau, M.W., Dale, B.E., Balan, V., 2008. Ethanolic fermentation of hydrolysates from ammonia fiber expansion (AFEX) treated corn stover and distillers grain without detoxification and external nutrient supplementation. Biotechnology and Bioengineering 99, 529-539.

Lee, S.H., Doherty, T.V., Linhardt, R.J., Dordick, J.S., 2009. Ionic liquid-mediated selective extraction of lignin from wood leading to enhanced enzymatic cellulose hydrolysis. Biotechnology and Bioengineering 102, 1368-1376.

Li, Q., He, Y.-C., Xian, M., Jun, G., Xu, X., Yang, J.-M., Li, L.-Z., 2009. Improving enzymatic hydrolysis of wheat straw using ionic liquid 1-ethyl-3-methyl imidazolium diethyl phosphate pretreatment. Bioresource Technology 100, 3570-3575.

Liu, C.G., Wyman, C.E., 2004. Impact of fluid velocity on hot water only pretreatment of corn stover in a flow through reactor. Applied Biochemistry and Biotechnology 113-116, 977-987.

Liu, L., Chen, H., 2006. Enzymatic hydrolysis of cellulose materials treated with ionic liquid [BMIM] Cl. Chinese Science Bulletin 51, 2432-2436.

Lloyd, T.A., Wyman, C.E., 2005. Combined sugar yields for dilute sulfuric acid pretreatment of corn stover followed by enzymatic hydrolysis of the remaining solids. Bioresource Technology 96, 1967-1977.

Miller, G.L., 1959. Use of dinitrosalicylic acid reagent for determination of reducing sugar. Analytical Chemistry 31, 426-428.

Mosier, N., Wyman, C., Dale, B., Elander, R., Lee, Y.Y., Holtzapple, M., Ladisch, M., 2005. Features of promising technologies for pretreatment of lignocellulosic biomass. Bioresource Technology 96, 673-686.

Obro, J., Harholt, J., Scheller, H.V., Orfila, C., 2004. Rhamnogalacturonan I in Solanum tuberosum tubers contains complex arabinogalactan structures. Phytochemistry 65, 1429-1438.

Pandey, K.K., Pitman, A.J., 2004. Examination of the lignin content in a softwood and a hardwood decayed by a brown-rot fungus with the acetyl bromide method and Fourier transform infrared spectroscopy. Journal of Polymer Science Part aPolymer Chemistry 42, 2340-2346.

Porchia, A.C., Sorensen, S.O., Scheller, H.V., 2002. Arabinoxylan biosynthesis in wheat characterization of arabinosyltransferase activity in Golgi membranes. Plant Physiology 130, 432-441.

Ramos, L.P., 2003. The chemistry involved in the steam treatment of lignocellulosic materials. Quimica Nova 26, 863-871.

Ruiz, R., Scarlata, C., Sluiter, J., Templeton, D., 2005. Determination of extractives in biomass. NREL Laboratory Analytical Procedure. National Renewable Energy Laboratory Golden, CO.

Sarath, G., Mitchell, R.B., Sattler, S.E., Funnell, D., Pedersen, J.F., Graybosch, R.A. Vogel, K.P., 2008. Opportunities and roadblocks in utilizing forages and small grains for liquid fuels. Journal of Industrial Microbiology and Biotechnology 35, 343-354.

Schell, D., Farmer, J., Newman, M., McMillan, J., 2003. Dilute-sulfuric acid pretreatment of corn stover in pilot-scale reactor. Applied Biochemistry and Biotechnology 105, 69-85.
Segal, L., Creely, J.J., Martin Jr, A.E., Conrad, C.M., 1959. An empirical method for estimating the degree of crystallinity of native cellulose using the X-ray diffractometer. Textile Research Journal 29, 786-794.

Sierra, R., Granda, C., Holtzapple, M.T., 2009. Short-term lime pretreatment of poplar wood. Biotechnology Progress 25, 323-332.

Simmons, B.A., Loque, D., Blanch, H.W., 2008. Next-generation biomass feedstocks for biofuel production. Genome Biology 9, 242.

Singh, S., Simmons, B.A., Vogel, K.P., 2009. Visualization of biomass solubilization and cellulose regeneration during ionic liquid pretreatment of switchgrass. Biotechnology and Bioengineering 104, 68-75.

Sluiter, A., Hames, B., Ruiz, R., Scarlata, C., Sluiter, J., Templeton, D., 2004a Determination of Structural Carbohydrates and Lignin in Biomass.LAP-002 NREL Analytical Procedure. National Renewable Energy Laboratory Golden, CO

Sluiter, A., Hames, B., Ruiz, R., Scarlata, C., Sluiter, J., Templeton, D., 2004b. Determination of Ash in Biomass. LAP-005 NREL Analytical Procedure. National Renewable Energy Laboratory Golden, CO.

Sun, N., Rahman, M., Qin, Y., Maxim, M.L., Rodriguez, H., Rogers, R.D., 2009. Complete dissolution and partial delignification of wood in the ionic liquid 1ethyl-3-methylimidazolium acetate. Green Chemistry 11, 646-655.

Suryawati, L., Wilkins, M.R., Bellmer, D.D., Huhnke, R.L., Maness, N.O., Banat, I.M., 2009. Effect of hydrothermolysis process conditions on pretreated switchgrass composition and ethanol yield by SSF with Kluyveromyces marxianus IMB4 Process Biochemistry 44, 540-545.

Tan, S.S.Y., MacFarlane, D.R., Upfal, J., Edye, L.A., Doherty, W.O.S., Patti, A.F., Pringle, J.M., Scott, J.L., 2009. Extraction of lignin from lignocellulose at atmospheric pressure using alkylbenzenesulfonate ionic liquid. Green Chemistry 11, 339345.

Wyman, C.E., Dale, B.E., Elander, R.T., Holtzapple, M., Ladisch, M.R., Lee, Y.Y., 2005. Comparative sugar recovery data from laboratory scale application of leading pretreatment technologies to corn stover. Bioresource Technology 96, 20262032.

Zhang, Y.-H.P., Lynd, L.R., 2004. Toward an aggregated understanding of enzymatic hydrolysis of cellulose: noncomplexed cellulase systems. Biotechnology and Bioengineering 88, 797-824.

Zhang, Y.H.P., Ding, S.Y., Mielenz, J.R., Cui, J.B., Elander, R.T., Laser, M., Himmel, M.E. McMillan, J.R., Lynd, L.R., 2007. Fractionating recalcitrant lignocellulose at modest reaction conditions. Biotechnology and Bioengineering 97, 214-223.

Zhao, H., Jones, C.I.L., Baker, G.A., Xia, S., Olubajo, O., Person, V.N., 2009. Regenerating cellulose from ionic liquids for an accelerated enzymatic hydrolysis. Journal of Biotechnology 139, 47-54.

Zhu, Z., Sathitsuksanoh, N., Vinzant, T., Schell, D.J., McMillan, J.D., Zhang, Y.H.P., 2009. Comparative study of corn stover pretreated by dilute acid and cellulose solvent-based lignocellulose fractionation: enzymatic hydrolysis, supramolecular structure, and substrate accessibility. Biotechnology and Bioengineering 103, 715-724. 